\title{
Micrococci Demonstrate a Phosphatase Activity Which Is Repressed by Phosphates and Which Can Be Differentiated from That of Staphylococci
}

\author{
G. SATTA, ${ }^{1 *}$ L. D'ANDREA, ${ }^{2}$ G. GRAZI, ${ }^{3}$ O. SORO,${ }^{3}$ AND P. E. VARALDO ${ }^{4}$ \\ Institute of Microbiology, Faculty of Medicine, Catholic University of the Sacred Heart, Rome, ${ }^{1}$ Institute of \\ Microbiology, University of Siena, Siena, ${ }^{2}$ Institute of Microbiology, University of Genoa, Genoa, ${ }^{3}$ and \\ Institute of Microbiology, University of Ancona, Ancona, ${ }^{4}$ Italy
}

\begin{abstract}
The phosphatase activities of 114 micrococcal strains belonging to seven different species and of an additional 150 unspeciated micrococcal strains were evaluated on solid media at various pHs containing or not containing phosphates. In the presence of phosphates, only nine strains (five unspeciated strains, one Micrococcus luteus strain, and three Micrococcus varians strains) yielded a positive reaction on plates at pH 8. In media (at pH 8) deprived of phosphates, in contrast, all but 15 strains demonstrated clear-cut phosphatase activity. Acid phosphatase could not be evaluated on solid media since none of the strains grew satisfactorily on plates at pH 5. The phosphatase activities of seven (one or two for each species, which included phosphatase-negative strains) of the strains whose colonies proved phosphatase negative at pH 8 and of 18 (two or three strains per species) of those with phosphatase-positive colonies were evaluated at $\mathrm{pH} 5$ and 8.5 in toluene-treated cells which had been grown in liquid media at pH 7 containing or not containing phosphates. All strains demonstrated distinct phosphatase activity at both pHs when grown in media not containing phosphates. In contrast, when strains were grown in the presence of such substances, virtually no activity was observed at $\mathrm{pH}$ 8.5, and, generally, a much reduced activity was observed at $\mathrm{pH}$. The phosphatase activity of micrococci of the various species (three to eight strains per species) was also compared with that of staphylococci of different species ( 5 to 10 strains per species) by the methyl green-phenolphthalein diphosphate method, the sensitivity of which can be varied by using different enzyme substrates. By using phenolphthalein diphosphate as an enzyme substrate, it was found that virtually all the different species of staphylococci yielded a positive reaction on plates not containing phosphates while almost all micrococci proved phosphatase negative with the methyl green-phenolphthalein diphosphate method. This indicates that the phosphatase activity of micrococci can easily be differentiated from that of staphylococci.
\end{abstract}

Of the metabolic properties generally exploited for defining and characterizing the different bacterial species, such as enzyme activities and sugar fermentation, only a few have so far been identified in micrococci. This leaves us with relatively few tests that, particularly in some species (see reference 17), can be used for characterizing the various strains of the group. This is rather unfortunate since it makes micrococcal species definition and identification difficult, particularly with the standard type of assays generally performed in routine clinical microbiology. However, it is likely that further studies may lead to identification of additional metabolic properties that may prove useful for characterization of this bacterial group.

Phosphatase activity is a property often evaluated as a test for species definition and identification $(3,10,12,15,48)$. However, it has not yet been extensively analyzed for micrococci. From the few studies performed, it was concluded that micrococci do not have this property $(3,11,16$, 21,31 ). However, in studying the phosphatase activity of the major staphylococcal species, some of which had previously been reported to be positive for this feature but most of which had been reported to be negative $(3,16,37)$, we have recently shown that all staphylococcal species analyzed demonstrated phosphatase activity (40). This was constitutive, however, in those species in which such activity had

\footnotetext{
* Corresponding author.
}

been recognized previously (Staphylococcus aureus, Staphylococcus epidermidis, and Staphylococcus xylosus), whereas in all the others (Staphylococcus simulans, Staphylococcus saprophyticus, Staphylococcus capitis, Staphylococcus hominis, Staphylococcus cohnii, and Staphylococcus haemolyticus) it was repressed by phosphates (40).

In view of this and in view of the potential utility of discovering novel metabolic features of micrococci, we analyzed this property in more than 250 strains isolated from humans and belonging to all the major human species. We show here that all strains carried an alkaline phosphatase activity which, in virtually all of them, was suppressed by growth in the presence of phosphates. We also show that this enzyme activity can easily be differentiated from that of staphylococci.

\section{MATERIALS AND METHODS}

Bacterial strains and strain identification. A total of 264 strains were isolated from the skin of human volunteers by using a selective medium described elsewhere $(5,39)$.

All strains were routinely grown on plates of tryptose phosphate agar (Difco Laboratories, Detroit, Mich.), unless otherwise indicated, and were incubated at $37^{\circ} \mathrm{C}$ for 16 to 48 h.

Media for assaying phosphatase activity. (i) Basal medium. The basal medium contained (per liter of distilled water) $10 \mathrm{~g}$ 
of peptonum siccum (Costantino, Turin, Italy), $10 \mathrm{~g}$ of yeast extract, $10 \mathrm{~g}$ of Difco meat extract (Difco), $5 \mathrm{~g}$ of $\mathrm{NaCl}$, and $2 \mathrm{~g}$ of glucose (medium $\mathrm{Ma}$ ).

(ii) Media Ma5, Ma7, and Ma8. To prepare medium Ma5, $\mathrm{Ma} 7$, or Ma8, the basal medium was supplemented with $15 \mathrm{~g}$ of agar; melted; brought to $\mathrm{pH} 5,7$, or 8 , respectively, by adding the required amount of $\mathrm{NaOH}$ from a $0.1 \mathrm{M}$ solution; and sterilized.

(iii) Media Ma5P, Ma7P, and Ma8P. In order to prepare medium Ma5P, Ma7P, or Ma8P, before agar was added, the basal medium was supplemented with $2 \mathrm{~g}$ of a mixture of monobasic and dibasic sodium phosphate sufficient to bring the $\mathrm{pH}$ of the medium to 5,7 , or 8 , respectively).

(iv) Ma media deprived of phosphates. Phosphates were removed as described elsewhere (30). After all the constituents listed above were dissolved, in order to remove the inorganic phosphates, $10 \mathrm{ml}$ of $\mathrm{NH}_{4}$ per liter of medium was added and the mixture was kept for $1 \mathrm{~h}$ at $40^{\circ} \mathrm{C}$ in order to allow the phosphates to precipitate. Precipitates were removed by filtering through filter paper, and the medium was warmed for $20 \mathrm{~min}$ at $90^{\circ} \mathrm{C}$ in order to allow the residual $\mathrm{NH}_{4}$ to evaporate. After this, if needed, $15 \mathrm{~g}$ of agar (Difco) per liter of medium was added and the $\mathrm{pH}$ was brought to 8 by the addition of $\mathrm{HCl}$, in most cases, or $\mathrm{NaOH}$ (medium $\mathrm{Mb} 8$ ). In some cases, before agar was added, $3 \mathrm{~g}$ of a suitable mixture of monobasic and dibasic sodium phosphates was added to give $\mathrm{pH} 8$ (medium $\mathrm{Mb} 8 \mathrm{P}$ ).

(v) Mc liquid media. In other experiments, after removal of precipitates by filtration and residual $\mathrm{NH}_{4}$ by evaporation, no agar was added, the $\mathrm{pH}$ was brought to 7 by the addition of $\mathrm{HCl}$ from a $1 \mathrm{M}$ solution, and the medium was sterilized and used as such (medium Mc7). Alternatively, after the medium was brought to $\mathrm{pH} 7,3 \mathrm{~g}$ of a mixture of monobasic and dibasic phosphates, suitable for maintaining $\mathrm{pH} \mathrm{7,} \mathrm{was}$ added (medium Mc7P).

Identification of micrococci. Identification of micrococci at the genus level was performed by methods proposed by others $(2,38)$ and by some of us $(36,45)$, while for identifying the micrococcal isolates the methods and scheme proposed by Kloos et al. (17) were adopted.

Determination of phosphatase activity of bacterial growth on agar plates. In order to assay phosphatase activity, to the above-mentioned media cooled to $45^{\circ} \mathrm{C}$ the stained phosphatase substrate paranitrophenyl phosphate (pNPP) (Sigma Chemical Co., St. Louis, Mo.) was added at a final concentration of $1 \mathrm{mg} / \mathrm{ml}$ from a sterile solution of $100 \mathrm{mg} / \mathrm{ml}$. Three isolated colonies of each of the strains to be tested were taken with a loop and deposited on the surface of the assay plates. As a rule, no more than 10 different strains were inoculated on each plate (containing pNPP). After inoculation, the plates were incubated at $37^{\circ} \mathrm{C}$ and observed at various time intervals until microbial growth (or the surface area around it or both) presented distinct yellow staining, or for $72 \mathrm{~h}$. Any clearly visible yellow staining of microbial growth (or of the plate surface around it) was taken to be a positive reaction.

In some experiments, bacterial growth phosphatase activity was also determined by the methyl green-phenolphthalein diphosphate (MGP) method previously described $(31,33$, 34). Briefly, to the melted media methyl green (Carlo Erba, Milan, Italy) and phenolphthalein diphosphate (Sigma), sterilized by filtration, were added at final concentrations of 25 and $1,000 \mathrm{mg} / \mathrm{ml}$, respectively, from 100 -fold-concentrated stock solutions.

Quantitative determination of the phosphatase activity of bacterial cells. The assay for quantitative determination of
TABLE 1. Phosphatase activity of micrococcal colonies of different species grown in media at different $\mathrm{pHs}$ and supplemented or not supplemented with phosphates

\begin{tabular}{|c|c|c|c|c|}
\hline \multirow{3}{*}{ Species (no. of strains) } & \multicolumn{4}{|c|}{$\begin{array}{l}\text { No. of strains yielding phosphate-positive } \\
\text { reactions }{ }^{a}\end{array}$} \\
\hline & \multicolumn{2}{|c|}{$\mathrm{pH} 7$} & \multicolumn{2}{|c|}{$\mathrm{pH} 8$} \\
\hline & Ma7P & Ma7 & Ma8P & Ma8 \\
\hline M. luteus (30) & 0 & 6 & 1 & 21 \\
\hline M. bylae (22) & 0 & 4 & 0 & 13 \\
\hline$M$. varians (21) & 3 & 5 & 3 & 13 \\
\hline M. sedentarius (15) & 0 & 3 & 0 & 10 \\
\hline$M$. roseus $(11)$ & 0 & 2 & 0 & 5 \\
\hline M. nishinomiyaenis (8) & 0 & 2 & 0 & 4 \\
\hline M. kristinae (7) & 0 & 1 & 0 & 2 \\
\hline Total & $3(3 \%)$ & $23(20 \%)$ & $4(3.5 \%)$ & $68(60 \%)$ \\
\hline
\end{tabular}

a The phosphatase activity of colonies was also assayed on plates of media at $\mathrm{pH} 5$ (Ma5 and Ma5P). No bacterial growth was observed on these media, and phosphatase activity could not be evaluated. Ma5, Ma7, and Ma8 are media not supplemented with $\mathrm{P}_{\mathrm{i}} \mathrm{s}$. Ma5P, Ma7P, and Ma8P are media supplemented with $P_{i} \mathbf{s}$.

the phosphatase activity of bacterial cells was basically performed as described by Pompei et al. (23), the only difference being that bacteria were grown in medium $\mathrm{Mc7}$ or Mc7P until the end of exponential growth and 10-ml samples from each were taken. Toluene-treated cells were suspended in $5 \mathrm{ml}$ of either $20 \mathrm{mM}$ acetate buffer $(\mathrm{pH} 5)$ or $20 \mathrm{mM}$ Tris hydrochloride buffer ( $\mathrm{pH} 8.5$ ) to a concentration of 2 optical density units. To these toluene-treated cells pNPP was added, and the mixture was incubated for $2 \mathrm{~h}$ at $37^{\circ} \mathrm{C}$.

\section{RESULTS}

Phosphatase activity of micrococcal colonies grown on media at different pHs containing different amounts of phosphates. The phosphatase activity of a total of 114 different micrococcal strains belonging to seven different species was first assayed on plates of media $\mathrm{Ma}$ and $\mathrm{MaP}$ at different pHs. Table 1 shows that most micrococcal strains demonstrated notable phosphatase activity. In strains of all species, such activity was always more frequent in medium Ma (not supplemented with $\mathrm{P}_{\mathrm{i}} \mathrm{s}$ ) and at $\mathrm{pH} 8$. No strains grew in the media at $\mathrm{pH} 5$.

After this, we assayed the phosphatase activities of the

TABLE 2. Phosphatase activity of micrococcal colonies grown on alkaline media deprived of or supplemented with phosphates

\begin{tabular}{llc}
\hline \multicolumn{1}{c}{ Species (no. of strains) } & \multicolumn{2}{c}{$\begin{array}{c}\text { No. of strains yielding } \\
\text { phosphate-positive reactions }\end{array}$} \\
\cline { 2 - 3 } & Mb8P & Mb8 \\
\hline M. luteus (30) & 1 & 30 \\
$M$. lylae (22) & 0 & 21 \\
$M$. varians (21) & 3 & 20 \\
M. sedentarius (15) & 0 & 13 \\
$M$. roseus (11) & 0 & 10 \\
$M$. nishinomiyaensis (8) & 0 & 7 \\
M. kristinae (7) & 0 & 6 \\
Unspeciated micrococci (150) & 5 & 142 \\
Total & $9(3 \%)$ & $249(94 \%)$ \\
\hline
\end{tabular}

${ }^{a} \mathrm{Mb} 8$ is a medium from which the phosphates were removed; Mb8P is medium Mb8 to which phosphates $(0.3 \%)$ were added. 
TABLE 3. Acidic and alkaline phosphatase activities of micrococcal cells treated with toluene after growth in the presence and absence of phosphates

\begin{tabular}{|c|c|c|c|c|}
\hline \multirow{3}{*}{ Strain } & \multicolumn{4}{|c|}{ Phosphatase activity (arbitrary units) at ${ }^{a}$ : } \\
\hline & \multicolumn{2}{|c|}{ pH 5} & \multicolumn{2}{|c|}{ pH 8.5} \\
\hline & Mc7P & Mc7 & Mc7P & Mc \\
\hline \multicolumn{5}{|l|}{ M. luteus } \\
\hline 01 & 10 & 86 & 0.8 & 160 \\
\hline 02 & 18 & 45 & 1 & 80 \\
\hline 03 & 13 & 70 & 0.8 & 110 \\
\hline \multicolumn{5}{|l|}{ M. lylae } \\
\hline 11 & 5 & 13 & 1.8 & \\
\hline 12 & 12 & 68 & 0.6 & 89 \\
\hline \multicolumn{5}{|l|}{ M. varians } \\
\hline 21 & 7 & 14 & 1.2 & 78 \\
\hline 22 & 16 & 38 & 0.5 & 84 \\
\hline 23 & 9 & 56 & 2 & 106 \\
\hline \multicolumn{5}{|l|}{ M. sedentarius } \\
\hline 31 & 4 & 80 & 8 & 130 \\
\hline 32 & 8 & 8 & 8 & 82 \\
\hline 33 & 6 & 6 & 6 & 82 \\
\hline \multicolumn{5}{|l|}{ M. roseus } \\
\hline 41 & 7 & 13 & 0.05 & 45 \\
\hline 42 & 15 & 36 & 1 & 6 \\
\hline \multicolumn{5}{|c|}{ M. nishinomiyaensis } \\
\hline 51 & 12 & 18 & 0.1 & 120 \\
\hline 52 & 32 & 55 & 0.7 & 94 \\
\hline \multicolumn{5}{|l|}{ M. kristinae } \\
\hline 61 & 20 & 37 & 2.5 & 162 \\
\hline 62 & 180 & 140 & 1.5 & 240 \\
\hline 63 & 34 & 28 & 0.2 & 67 \\
\hline
\end{tabular}

${ }^{a}$ The results are the means of three different assays. Mc7 is a liquid medium at $\mathrm{pH} 7$ from which the phosphates were removed; $\mathrm{Mc} 7 \mathrm{P}$ is medium $\mathrm{Mc} 7$ to which phosphates $(0.3 \%)$ were added.

above-mentioned 114 strains and of an additional 150 strains (not identified at the species level) in a medium from which phosphates had been removed (medium $\mathrm{Mb}$; see Materials and Methods) and in this medium supplemented with $0.3 \%$ phosphates (medium MbP), both at $\mathrm{pH} 8$. Table 2 shows that almost all (94\%) strains demonstrated phosphatase activity in the phosphate-deprived medium (Mb8), while only very few $(3 \%)$ demonstrated such activity when grown in the medium supplemented with phosphates (Mb8P). In the strains identified at the species level, all species except Micrococcus luteus contained at least one strain that yielded a negative reaction in the absence of phosphates.

Acidic and alkaline phosphatase activities of micrococcal cells grown in liquid media containing and not containing phosphates. A number of strains of each different species were grown in a liquid medium deprived of phosphates (medium $\mathrm{Mc}$ ) at $\mathrm{pH} 7$ and in the same medium supplemented with $0.3 \% \mathrm{P}_{\mathrm{i}} \mathrm{s}$ (medium $\mathrm{McP}$ ). The phosphatase activity of the bacterial cells was then evaluated at pHs 5 and 8.5. Table 3 shows that, at $\mathrm{pH} 8.5$, all strains demonstrated notable phosphatase activity when grown in the absence of phosphates. In contrast, they showed a very modest or virtually no activity when grown in the medium supplemented with phosphates. The only partial exceptions were the Micrococcus sedentarius strains which showed also a certain amount
TABLE 4. Acidic and alkaline phosphatase activities of toluenetreated cells of the micrococcal strains whose colonies were phosphatase negative

\begin{tabular}{|c|c|c|c|c|}
\hline \multirow{3}{*}{ Strain } & \multicolumn{4}{|c|}{ Phosphatase activity (arbitrary units) at ${ }^{a}$ : } \\
\hline & \multicolumn{2}{|c|}{ pH 5} & \multicolumn{2}{|c|}{$\mathrm{pH} 8$} \\
\hline & Mc7P & Mc7 & Mc7P & Mc7 \\
\hline M. varians 88 & 7 & 12 & 0.5 & 0.4 \\
\hline \multicolumn{5}{|c|}{ M. nishinomiyaensis } \\
\hline 39 & 26 & 35 & 13 & 11 \\
\hline 2699 & 4 & 6 & 0.5 & 21 \\
\hline \multicolumn{5}{|l|}{ M. roseus } \\
\hline 117 & 8 & 9 & 1 & 2 \\
\hline 110 & 7 & 13 & 1 & 23 \\
\hline \multicolumn{5}{|l|}{ M. kristinae } \\
\hline 96 & 17 & 27 & 1 & 25 \\
\hline 2690 & 11 & 7 & 3 & 6 \\
\hline
\end{tabular}

${ }^{a}$ The results are the means of three different assays. For descriptions of media, see Table 3 , footnote $a$.

of activity after growth in the presence of phosphates. In the assays performed at $\mathrm{pH} 5$, all strains demonstrated some phosphatase activity; however, such activity was always lower than that observed at $\mathrm{pH} 8.5$ and, although mostly reduced, was never fully suppressed by growth in the presence of phosphates. With the strains of some species, such as Micrococcus kristinae, no reduction of activity was observed after growth in the presence of phosphates, while, with strains of other species, such as Micrococcus nishinomiyaensis and Micrococcus roseus, the reduction observed was very slight.

Finally, under the above-mentioned conditions, we also evaluated the phosphatase activity of seven strains which were negative in all test conditions based on solid media. Table 4 shows that, in this different assay, they all turned out to be less active than the other strains though they all showed some activity. In particular, one Micrococcus varians, one $M$. nishinomiyaensis, one $M$. roseus, and one $M$. kristinae strain was more active at the acidic than at the alkaline $\mathrm{pH}$.

Comparative analysis of the phosphatase activity of micrococcal and staphylococcal colonies by the MGP and pNPP methods. A method for detecting phosphatase activity of bacterial colonies (MGP method) which can be prepared in formulations of different sensitivities has been previously described $(23,31,34)$. It was shown in particular that, with this method, phosphatase activity could be detected in all members of the family Enterobacteriaceae or only in the most active of them, depending on the phosphatase substrate used $(23,33,41)$. Since, with the assays in liquid media performed both with micrococci (this work) and with staphylococci (see references 31 and 40 ), we observed a stronger activity in the latter strains than in the former, we considered the possibility that this method might be capable of differentiating between micrococcal and staphylococcal phosphatase. Table 5 shows that this indeed was the case. In the medium supplemented with phosphates, a positive reaction was observed only in all strains of Staphylococcus aureus, Staphylococcus epidermidis, and Staphylococcus xylosus but in no other staphylococci and in none of the micrococci. In the medium deprived of phosphates, all strains of almost all staphylococcal species also yielded a positive reaction, 
TABLE 5. Detection of phosphatase activity by the MGP method in colonies of staphylococci and micrococci of different species

\begin{tabular}{|c|c|c|c|c|}
\hline \multirow{3}{*}{$\begin{array}{l}\text { Bacterial species (no. of } \\
\text { strains) }\end{array}$} & \multicolumn{4}{|c|}{ Phosphatase reaction $(n)$ in $^{a}$ : } \\
\hline & \multicolumn{2}{|c|}{$\mathrm{Mb} 8 \mathrm{P}$} & \multicolumn{2}{|c|}{$\mathrm{Mb} 8$} \\
\hline & pNPP & MGP & pNPP & MGP \\
\hline S. aureus $(10)$ & $+(10)$ & $+(10)$ & $+(10)$ & $+(10)$ \\
\hline$S$. epidermidis (10) & $+(10)$ & $+(10)$ & $+(10)$ & $+(10)$ \\
\hline S. xylosus (7) & $+(10)$ & $+(10)$ & $+(10)$ & $+(10)$ \\
\hline S. hominis (5) & $-(5)$ & $-(5)$ & $+(5)$ & $+(4)$ \\
\hline S. haemolyticus (5) & $-(5)$ & $-(5)$ & $+(5)$ & $+(5)$ \\
\hline S. saprophyticus (5) & $-(5)$ & $-(5)$ & $+(5)$ & $+(5)$ \\
\hline S. simulans $(8)$ & $-(8)$ & $-(8)$ & $+(8)$ & $+(8)$ \\
\hline S. cohnii (5) & $-(5)$ & $-(5)$ & $+(5)$ & $+(4)$ \\
\hline S. capitis (5) & $-(5)$ & $-(5)$ & $+(5)$ & $+(4)$ \\
\hline S. warneri (8) & $-(8)$ & $-(5)$ & $+(8)$ & $+(4)$ \\
\hline M. luteus (8) & $-(8)$ & $-(8)$ & $+(8)$ & $-(8)$ \\
\hline M. lylae (6) & $-(6)$ & $-(6)$ & $+(6)$ & $-(6)$ \\
\hline M. varians (5) & $-(5)$ & $-(8)$ & $+(5)$ & $-(5)$ \\
\hline M. sedentarius (6) & $-(6)$ & $-(6)$ & $+(6)$ & $-(6)$ \\
\hline M. roseus (3) & $-(3)$ & $-(3)$ & $+(3)$ & $-(3)$ \\
\hline M. nishinomiyaensis (3) & $-(3)$ & $-(3)$ & $+(3)$ & $-(3)$ \\
\hline M. kristinae (3) & $-(3)$ & $-(3)$ & $+(3)$ & $-(3)$ \\
\hline
\end{tabular}

a pNPP and MGP indicate phosphatase activity evaluated by a standard method with pNPP as the substrate and by the novel MGP method (see Materials and Methods), respectively. Mb8P is medium Mb8 to which phosphates $(0.3 \%)$ were added; $\mathrm{Mb} 8$ is a medium from which the phosphates were removed.

while virtually all micrococci yielded a negative reaction in this medium. All strains of both staphylococci and micrococci, in contrast, appeared to be phosphatase positive when this activity was evaluated by a conventional method on plates deprived of phosphates but containing pNPP as the enzyme substrate.

\section{DISCUSSION}

This work has shown that micrococci of all major species carry an acidic and an alkaline phosphatase. Of the two enzymes, the alkaline one appears to be regulated and is clearly fully repressed by phosphates (although apparentiy not to the same extent in all species) in virtually all strains. Alkaline phosphatases regulated by phosphates have been previously described for several other bacterial species $(4$, 13, 40, 44). The acidic phosphatase was much less influenced by phosphates, although growth in their presence generally led to a clearly reduced apparent enzyme activity.

The demonstration that micrococci have a phosphatase activity is interesting because it leads to a better characterization of the properties of this bacterial genus and because it provides us with an additional means potentially capable of contributing to a more reliable differentiation and definition of this microbial group. Micrococci, in fact, do not show many biochemical activities (with the exceptions of strains of a few species only) that can be easily detected, and the discovery of such a property suggests the possibility of developing a novel tool for identifying different species. As has been shown for bacteriolytic enzymes of staphylococci $(35,46,47)$, enterococci (25), and pseudomonads (32), it is possible that the phosphatase of micrococci may have properties that allow its differentiation from that of other microbial species. This possibility is supported by the fact that the phosphatase activity of micrococci is not detected by the MGP method, which suggests the possibility of exploiting this enzyme for differentiation of staphylococci from micrococci. The facts that specific inhibitors of a number of phosphatases have been described $(6,18,19,27)$ and that substrate specificity may be different in the different enzymes $(8,29)$ suggest that methods capable of identifying the phosphatase of some species may be devised.

The differences in the phosphatase activities of staphylococci and micrococci demonstrated by the MGP method are very probably merely quantitative. However, we $(24,28)$ and others $(42,43)$ have analyzed the properties of phosphatases of members of the family Enterobacteriaceae both at the physiologic (24) and genetic $(28,42,43)$ levels and have found strong similarities among strains of the same species and differences in others. This makes it likely that differences exist not only among phosphatases of staphylococci and micrococci but also among phosphatases of different micrococcal species. It seems possible that, by assaying the phosphatase activity of the various micrococcal species in media of different $\mathrm{pHs}$ or in media containing different substrates, differences in the enzyme activities of the various micrococcal species or in those of the different genera of the Micrococcaceae family may be observed.

The phosphatase activity of micrococci has been assayed previously by others and was reported to be absent by all those performing such assays $(3,11,16,21)$, including us $(31$, $45)$. The findings of this work, however, do not disprove these previous findings, since we have shown here that the growth medium drastically influences apparent phosphatase activity of micrococci. The phosphate contents of the media in which the micrococci were grown were not taken into account in the previous studies. It is very likely that the media employed contained an amount of phosphates sufficient for repressing the micrococcal enzyme. A similar possibility is strongly supported by the fact that, in our experiments, the phosphates contained in different types of commercial peptones (data not shown) caused repression of the phosphatase activity of most micrococcal strains, and the media used in previous works almost always contained commercial peptones. In contrast, the media in which we detected the phosphatase activity of micrococci were only those from which most of the phosphates contained in the peptone were removed.

We had previously demonstrated that among a total of more than 1,000 strains of the family Enterobacteriaceae belonging to more than 14 different species, the colonies of practically all the strains were phosphatase positive (33). Phosphatase activity has been demonstrated for many other microorganisms at very different stages of bacterial evolution, such as, for instance, mycoplasmas $(9,20)$, mycobacteria $(1,14)$, anaerobes $(26)$, yeasts $(7)$, and algae $(22)$. These enzymes might be present in all microorganisms, and analysis of the genes encoding them in different species might prove exclusively useful in studies of bacterial evolution and for establishing the degree of relatedness of various bacterial species.

\section{ACKNOWLEDGMENTS}

This work was supported by CNR, target project BTBS, grant 92.01253.PF70; target project ACRO, grant 92.02264.PF39; and target project FATMA, grant 93.00732.PF41.

We also thank Laura Curti for expert secretarial work and Anthony Steele for reviewing the English version of the paper. 


\section{REFERENCES}

1. Andrejew, A. 1968. Phosphatase activity of mycobacteria. Ann. Inst. Pasteur (Paris) 115:11-12.

2. Baird-Parker, A. 1974. The basis for the present classification of staphylococci and micrococci. Ann. N.Y. Acad. Sci. 236:7-14.

3. Baird-Parker, A. C. 1963 . A classification of micrococci and staphylococci based on physiological and biochemical tests. J. Gen. Microbiol. 30:409-427.

4. Bhatti, A. R., and J. Done. 1974. On the presence of two types of alkaline phosphatase in Serratia marcescens. Microbios 11:203-213.

5. Curry, J. C., and G. E. Borovian. 1976. Selective medium for distinguishing micrococci from staphylococci in the clinical laboratory. J. Clin. Microbiol. 4:455-457.

6. Doellgast, G. J., and W. H. Fishman. 1977. Inhibition of human placental-type alkaline phosphatase variants by peptides containing L-leucine. Clin. Chim. Acta 75:449-454.

7. Farid, A., M. Atia, and M. Hassouna. 1980. Production of phosphatase enzymes by different Candida species. Mykosen 23:640-643.

8. Garen, A., and C. Levinthal. 1960. A fine-structure genetic and chemical study of the enzyme alkaline phosphatase of $E$. coli. I. Purification and characterization of alkaline phosphatase. Biochim. Biophys. Acta 38:470-483.

9. Hill, A. C. 1977. The metabolic inhibition test for mycoplasmas based on phosphatase production. J. Hyg. Camb. 79:391-393.

10. Holt, R. 1969. The classification of staphylococci from colonized ventriculo-atrial shunts. J. Clin. Pathol. 22:475-482.

11. International Committee on Systematic Bacteriology Subcommittee on the Taxonomy of Staphylococci and Micrococci. 1976. Minutes of the meeting, 9 September 1975. Appendix 1, identification of staphylococci. Int. J. Syst. Bacteriol. 26:332-334.

12. Ivanovics, G., and J. Foldes. 1958. Problems concerning the phylogenesis of Bacillus anthracis. Acta Microbiol. Hung. 5:89109.

13. Kander, R. J., J. F. Ney, and D. H. Brown. 1968. A repressible alkaline phosphatase in Neurospora crassa. J. Biol. Chem. 243:3076-3082.

14. Kappler, W. 1965. On the differentiation of mycobacteria by the phosphatase test. Beitr. Klin. Erforsch. Tuberk. Lungenkr. 130:225-226.

15. Killian, M. 1976. A taxonomic study of the genus Haemophilus with the proposal of a new species. J. Gen. Microbiol. 93:9-76.

16. Kloos, W. E., and K. H. Schleifer. 1975. Isolation and characterization of staphylococci from human skin. II. Descriptions of four new species: Staphylococcus warneri, Staphylococcus capitis, Staphylococcus hominis, and Staphylococcus simulans. Int. J. Syst. Bacteriol. 25:62-79.

17. Kloos, W. E., T. G. Tornabene, and K. H. Schleifer. 1974. Isolation and characterization of micrococci from human skin, including two new species: Micrococcus lylae and Micrococcus kristinae. Int. J. Syst. Bacteriol. 24:79-101.

18. Komoda, T., and Y. Sakagishi. 1977. Inhibition of alkaline phosphatase by sialic acid. Biochim. Biophys. Acta 482:79-88.

19. Landt, M., S. C. Boltz, and L. C. Butler. 1978. Alkaline phosphatase: affinity chromatography and inhibition by phosphonic acid. Biochemistry 17:915-919.

20. Makci, M. A. 1971. Phosphatase activity of some Mycoplasma species. J. Hyg. Epidemiol. Microbiol. Immunol. 15:417-423.

21. Oeding, P., and A. Digranes. 1977. Classification of coagulasenegative staphylococci in the diagnostic laboratory. Acta Pathol. Microbiol. Scand. Sect. B 85:136-142.

22. Patni, N. J., and S. Aaronson. 1977. Stimulation of acid phosphatase secretion in a lower eukaryote, Ochromonas danica, by specific organic phosphates. Biochim. Biophys. Acta 478:209214.

23. Pompei, R., G. Cornaglia, A. Ingianni, and G. Satta. 1990. Use of a novel phosphatase test for simplified identification of species of the tribe Proteeae. J. Clin. Microbiol. 28:1214-1218.

24. Pompei, R., A. Ingianni, G. Foddis, G. Di Pietro, and G. Satta. 1993. Patterns of phosphatase activity among enterobacterial species. Int. J. Syst. Bacteriol. 43:174-178.

25. Pompei, R., M. C. Thaller, F. Pittaluga, O. Flore, and G. Satta.
1992. Analysis of bacterial activity patterns, a novel approach to the taxonomy of enterococci. Int. J. Syst. Bacteriol. 42:37-43.

26. Porschen, R. K., and E. H. Spaulding. 1974. Phosphatase activity of anaerobic organisms. Appl. Microbiol. 27:744-747.

27. Razababu, C., and B. Axelrod. 1978. Site specific inactivation of phosphatases by ferrate ion. Arch. Biochem. Biophys. 188:3136.

28. Riccio, M. L., G. Lombardi, A. Chiesurin, and G. Satta. An in vivo assay for rapid screening and detection of genes encoding distinct species of phosphatases: its use for the molecular cloning of four different genes. Submitted for publication.

29. Rogers, D., and F. J. Reithel. 1960. Acid phosphateses of Escherichia coli. Arch. Biochem. Biophys. 89:97-104.

30. Rubin, G. M. 1974. Three forms of the 5.8S ribosomal RNA species in Saccharomyces cerevisiae. Eur. J. Biochem. 41:197202.

31. Satta, G., G. Grazi, P. Varaldo, and R. Fontana. 1979. Detection of bacterial phosphatase activity by means of an original and simple test. J. Clin. Pathol. 32:391-395.

32. Satta, G., F. Palmas, P. E. Varaldo, G. Grazi, O. Soro, and R. Pompei. 1983. Analysis of the bacteriolytic pattern as a tool for species separation and identification in Micrococcaceae, streptococci and Pseudomonadaceae, p. 309-316. In K. H. Spitzy and K. Karrer (ed.), Proceedings of the 13th International Congress on Chemotherapy. H. Egermann Verlag, Vienna.

33. Satta, G., R. Pompei, G. Grazi, and G. Cornaglia. 1988. Phosphatase activity is a constant feature of all isolates of all major species of the family Enterobacteriaceae. J. Clin. Microbiol. 26:2637-2641.

34. Satta, G., R. Pompei, and A. Ingianni. 1984. The selective staining mechanism of phosphatase producing colonies in diphosphate phenolphthalein methyl green method for the detection of bacterial phosphatase activity. Microbiologica (Pavia) 7:159-170.

35. Satta, G., P. E. Varaldo, G. Grazi, and R. Fontana. 1977. Bacteriolytic activity in staphylococci. Infect. Immun. 16:3742.

36. Satta, G., P. E. Varaldo, M. Tenca, and L. Rodin. 1978. The relevance of bacterial lytic activity in the taxonomy of the micococcaceae: failure of its production by micrococcus and planococcus as opposed to staphylococcus. J. Gen. Microbiol. 109:385-388.

37. Schleifer, K. H., and W. E. Kloos. 1975. Isolation and characterization of staphylococci from human skin. I. Amended descriptions of Staphylococcus epidermidis and Staphylococcus saprophyticus and descriptions of three new species: Staphylococcus cohnii, Staphylococcus haemolyticus, and Staphylococcus xylosus. Int. J. Syst. Bacteriol. 25:50-61.

38. Schleifer, K. H., and W. E. Kloos. 1975. A simple test system for the separation of staphylococci from micrococci. J. Clin. Microbiol. 1:337-338.

39. Smith, R. F. 1969. A medium for the study of the ecology of human cutaneous diptheroids. J. Gen. Microbiol. 57:411-417.

40. Soro, O., G. Grazi, P. E. Varaldo, and G. Satta. 1990. Phosphatase activity of staphylococci is constitutive in some species and repressed by phosphates in others. J. Clin. Microbiol. 28:2707-2710.

41. Thaller, M. C., F. Berlutti, F. Pantanella, R. Pompei, and G. Satta. 1992. Modified MacConkey medium which allows simple and reliable identification of Providencia stuartii. J. Clin. Microbiol. 30:2054-2057.

42. Thaller, M. C., F. Berlutti, M. C. Riccio, and G. M. Rossolini. 1992. A species specific DNA probe for Providencia stuartii identification. Mol. Cell. Probes 6:417-422.

43. Thaller, M. C., F. Berlutti, S. Schippa, and G. M. Rossolini. Cloning and sequencing the pho $\mathrm{C}$ gene of Morganella morganii coding for the principal $p$-nitrophenyl phosphate-hydrolyzing acid phosphatase: a new member of the family of conserved acid phosphatases. Submitted for publication.

44. Torriani, A. 1960. Influence of inorganic phosphate in the formation of phosphatases by Escherichia coli. Biochim. Biophys. Acta 38: $460-479$.

45. Varaldo, P. E., G. Grazi, G. Cisani, and G. Satta. 1979. Routine 
separation of staphylococci from micrococci based on bacteriolytic activity production. J. Clin. Microbiol. 9:147-148.

46. Varaldo, P. E., and G. Satta. 1978. Grouping of staphylococci on the basis of their bacteriolytic-activity patterns: a new approach to the taxonomy of the Micrococcaceae. II. Main characters of 1,054 strains subdivided into "lyogroups." Int. J. Syst. Bacteriol. 28:148-153.
47. Varaldo, P. E., G. Satta, G. Grazi, and C. A. Romanzi. 1978. Grouping of staphylococci on the basis of their bacteriolyticactivity patterns: a new approach to the taxonomy of the Micrococcaceae. I. Identification of six different "lyogroups." Int. J. Syst. Bacteriol. 28:141-147.

48. Zelezna, I. 1962. Phosphatase activity of Rhizobium. Acta Microbiol. Pol. 11:329-334. 